\title{
Systemic therapy in the curative treatment of head and neck squamous cell cancer: a systematic review
}

\author{
Eric Winquist ${ }^{1 *}$, Chika Agbassi ${ }^{5}$ D, Brandon M. Meyers ${ }^{3}$, John Yoo ${ }^{2}$, Kelvin K. W. Chan ${ }^{4}$
}

and the Head and Neck Disease Site Group

\begin{abstract}
Objective: To review the available evidence and make recommendations regarding use of systemically administered drugs in combination or in sequence with radiation (RT) and/or surgery for cure and/or organ preservation in patients with locally advanced nonmetastatic (Stage III to IVB) squamous cell carcinoma of the head and neck (LASCCHN).

Method: Recognizing the Meta-analysis of Chemotherapy in Head and Neck Cancer (MACH-NC) group reports have de facto guided practice since 2000, we searched for systematic reviews in the MEDLINE, EMBASE and Cochrane Database of Systematic Reviews published from January 2000 to February 2015 in reference to 4 research questions. A search was also conducted for randomized trials (RCTs) up to February 2015 not included in the meta-analyses.

Result: The MACH-NC reports, 5 additional meta-analyses, and 30 RCTs not included by MACH-NC were identified. For chemotherapy, MACH-NC findings showing improved overall survival with concomitant chemoRT did not require modification. High-dose cisplatin was most commonly studied. We confirmed this benefit with cisplatin monotherapy in patients treated with with postoperative concurrent chemoRT. Other than cetuximab, no targeted agents and radiosensitizers studied in RCTs were shown effective. TPF induction chemotherapy was superior to PF for tumor response and larynx preservation but not survival. Larynx preservation was reported with both CRT and induction chemotherapy approaches.

Conclusion: ChemoRT with cisplatin at least $40 \mathrm{mg} / \mathrm{m} 2$ per week given as radical or postoperative adjuvant remains a standard treatment approach for LASCCHN that improves overall survival but increases toxicity. 5-FU plus platinum is supported by less data but may be a reasonable alternative for patients unsuitable for cisplatin. Of note, stratification of outcomes by HPV-status was not available but outcomes for oropharynx cancer appeared similar to other subsites in chemoRT RCTs. No RCTs have yet demonstrated superiority or non-inferiority of cetuximab-RT to CRT. In view of this, cetuximab-RT is suggested only for patients not candidates for CRT. Taxane-based triplet induction chemotherapy is superior to doublets for rapid tumour downsizing and for larynx preservation, but does not improve overall survival and should be used with primary G-CSF prophylaxis. Further investigation of induction approaches for larynx preservation may be warranted.
\end{abstract}

Keywords: Systematic review, Squamous cell carcinoma, Head and Neck, Human papilloma Virus, Locally advanced, Systemic chemotherapy, Induction chemotherapy, Concurrent chemotherapy

\footnotetext{
* Correspondence: Eric.Winquist@lhsc.on.ca

'Department of Oncology, Western University and London Health Science Centre, 790 Commissioners Rd East, PO Box 5010 London, Ontario N6A 5W9

London, Ontario, Canada

Full list of author information is available at the end of the article
} 


\section{Background}

Squamous cell carcinoma is the most common malignant tumour occurring in the head and neck region, accounting for more than $90 \%$ of all head and neck cancers [1]. Cutaneous SCC is most common in areas that are most exposed to the sun such as the scalp, face, ears, and lips; is usually cured with local therapy; and will not be considered further. More serious, debilitating, and potentially life threatening squamous cell carcinoma can affect the mucosal linings of the oral and nasal cavities, paranasal sinuses, nasopharynx, oropharynx, hypopharynx, and larynx with the most common sites being the larynx, oral cavity, and oropharynx [1]. These cancers will be the focus of this guideline, and it is notable that squamous cell carcinoma of the head and neck (SCCHN) is ranked the sixth most common cancer world-wide with more than 500,000 new cases and 300,000 deaths reported annually [1].

Tobacco use has long been identified as an important risk factor. Over the past decade, the importance of human papillomavirus (HPV) in the pathogenesis of oropharyngeal cancers has been recognzied. These cancers continue to increase in incidence, and often affect younger patients. The randomized controlled trials (RCTs) considered in this guideline were conducted without recognition of this important biological prognostic factor. Consequently, the results of individual RCTs should be interpreted cautiously, as inadvertent imbalance in the proportion of patients with HPV-related tumours could influence trial results. The pooled results of these trials should also be applied to patients with HPV-related SCCHN cautiously, as the optimal treatment approaches for these patients remain to be defined.

Depending on the disease stage at presentation, the primary management strategies for patients with SCCHN consist of surgery and/or radiation therapy (RT). The cure rates for early-stage (Stages I and II) cancers treated with radiotherapy or surgery alone are high. A key challenge in the management of SCCHN is that the majority of patients have locally advanced disease (Stages III to IVB) at first presentation. Individual patient data meta-analyses of the Meta-analysis of Chemotherapy in Head and Neck Cancer (MACH-NC) group review have provided major insights into the role of chemotherapy in the curative treatment of locally advanced squamous cell cancer of the head and neck (LASCCHN), and have served as de facto practice guidelines since their publication in 2000 and update in 2009, which includes randomized controlled trials (RCTs) reported 1965 to 2000 [2-4]. These analyses demonstrated a lack of overall survival benefit with the use of induction or adjuvant chemotherapy but an improved overall survival with concomitant (concurrent or alternating) chemotherapy combined with RT [2-4]. The absolute overall survival benefit with concomitant chemotherapy at five years was $6.5 \%$ and the hazard ratio (HR) of death was 0.81 (95\% confidence interval [CI], 0.78 to $0.86 ; p<0.001$ ) [2-4]. Concurrent chemotherapy with radiation (CRT) is the usual approach in Ontario and a focus of this review. Radiotherapy has recently evolved with the adoption of techniques allowing more precise delivery (e.g., intensitymodulated radiotherapy) replacing conventional RT.

As RCT evidence has continued to emerge over the past decade, and novel clinical treatments (including epidermal growth factor receptor [EGFR]-targeted drugs, radiosensitizers, and taxane-based induction chemotherapy) have continued to be developed, the Working Group of the Head and Neck Cancer DSG developed this evidentiary base to inform recommendations as part of a clinical practice guideline. Since the MACH-NC meta-analyses are comprehensive and have served as a de facto practice guideline, to avoid duplicating them, they were used as a reference point for the evidentiary base of this guideline with the objective of addressing the research questions outlined below.

\section{Research question(s)}

1. In patients with unresected LASCCHNs, what are the chemotherapy regimens that, administered concurrently with conventional or intensified radiotherapy, are superior or equivalent to other regimens on important outcomes such as tumour response rate, survival rate, and organ preservation with fewer toxicity/adverse events (AEs)?

2. In postoperative patients with resected LASCCHN, what is the optimal chemotherapy regimen that can be administered concurrently with conventional radiotherapy?

3. Compared to chemoradiotherapy, can targeted agents or radiosensitizers improve or maintain outcomes, with reduced toxicity/AEs, when used alone or in addition to primary radiotherapy in the treatment of patients with LASCCHN?

4. In patients with LASCCHN, what induction chemotherapy regimens that are superior or equivalent to others on important outcomes such as tumour response rate, survival rate, and organ preservation with fewer toxicity/AEs?

\section{Methods}

A search for existing systematic reviews on the role of systemic chemotherapy in the management of LASCCHN was conducted. Systematic reviews published as a component of practice guidelines that were not considered suitable for adaptation or endorsement were also considered eligible for inclusion in the evidence base. The AMSTAR tool [5] was used to determine minimum 
threshold for methodological quality. In addition to the selection of suitable systematic reviews, a search for primary literature published from January 2000 through February 2015 was conducted. The year 2000 was used as a cut-off to minimize duplication of the MACH-NC metaanalyses $[3,4,6]$. The proceedings of the meetings of the American Society of Clinical Oncology (ASCO), American Society for Radiation Oncology (ASTRO), European Society for Medical Oncology (ESMO), and European Society for Therapeutic Radiation and Oncology (ESTRO) were searched for relevant abstracts. The reference lists of studies deemed eligible for inclusion were also hand searched for additional citations.

A review of the titles and abstracts that resulted from the electronic searches was carried out by one reviewer (CA). Studies were included if they were systematic reviews, meta-analyses, or RCTs evaluating the role of induction or concurrent chemotherapy in the management of non-metastatic SCCHN, specifically in the hypopharynx, larynx, trachea, oral cavity, and oropharynx regions, or RCTs comparing one drug regimen including targeted agents and radiosensitizers with another drug regimen alone or in combination with locoregional treatment (radiotherapy and/or surgery). The studies had to report at least one of the following outcomes: overall survival rate (OS), disease free survival rate (DFS), tumour response rate, larynx preservation, Grade 3/4 toxicity or quality of life.

Data from the included studies were extracted by the project research methodologist. When multiple RCTs with similar experimental and control arms were available, a meta-analysis was conducted using the Review Manager software (RevMan 5.3) provided by the Cochrane Collaboration [7]. For all outcomes, the generic inverse variance model with random effects was used. For time-to-event outcomes, hazard ratios, rather than the number of events at a certain time point, were the preferred statistic for meta-analysis. If the HR and/ or its standard error were not reported, they were derived from other information reported in the study, using the methods described by Parmar et al. [8]. Statistical heterogeneity was calculated using the $\chi^{2}$ test for heterogeneity and the $\mathrm{I}^{2}$ percentage. A probability level for the $\chi^{2}$ statistic less than or equal to $10 \%(p \leq 0.10)$ and/or an $\mathrm{I}^{2}$ greater than $50 \%$ was considered indicative of statistical heterogeneity.

\section{Results}

The search for systematic reviews yielded 214 references including 14 conference abstracts published between 2000 and 2014. Out of these 214 reports, 21 reviews were considered potentially eligible and full text reports of 21 reviews were retrieved and reviewed. Ten reviews with pooled analysis [2, 3, 9-16] were identified as potentially relevant to the topic areas covered by this guideline. Three reports focused on induction chemotherapy, two on postoperative chemotherapy, two on targeted agents, one on concurrent chemotherapy and in two reports, the timing of chemotherapy not specified. After full text review, five meta-analyses [2-4, 14-16] were included. Four [9-11, 13] were excluded because they reviewed RCTs of non-LASCCHN, and one metaanalysis [12] was excluded following AMSTAR assessment. No further discussions of these references will be made in this guideline. Although the high quality MACH-NC meta-analysis [3] was updated in 2009 by Pignon et al. [4], the trials that formed the basis of the analysis were older studies and this applies to the meta-analysis reported by Budach et al. [14] as well. Their findings will be used as the sole reference for the studies conducted before year 2000 .

\section{Study design and quality}

The quality of included studies was assessed using the Cochrane Risk of Bias Assessment Tool and other quality features such as the follow-up rate and duration, sample size, and power calculation. Not all quality features were reported by all the studies but a majority reported using the intention-to-treat protocol as the basis of analysis. The median follow-up period ranged from six to 120 months. Although baseline characteristics for included patients were well balanced between treatment arms, it is important to note the possibility of an unintentional imbalance in patient population since none of these trials were stratified based on HPV status.

Potentially eligible RCTs identified were Phase II and III RCTs conducted between 1990 and 2013 with sample sizes ranging from 37 participants to 966 participants. The patient population was similar across studies, consisting of patients with previously untreated nonmetastatic Stage III to IVB SCCHN of the oral cavity, oropharynx, hypopharynx, and larynx. The performance status was measured by the Karnofsky Performance Score, Eastern Cooperative Oncology Group (ECOG), or World Health Organization (WHO) scales. Eleven trials were Phase II RCTs that addressed outcomes or comparisons not directly relevant to the research questions and were excluded: four novel induction regimens [17-20], four novel concurrent regimens [21-24], one adjuvant chemotherapy [25], one adjuvant cetuximab [26], one radiosensitizers with non-standard control arms [27]. Eleven of the RCTs identified had been included in the MACH-NC meta-analysis; including one published report of a previously unpublished RCT [28] and seven updated reports of six previously published RCTs [11, 29-34]. Four RCTs [35-38] identified were also included in the review of larynx preservation reported by Denaro et al. [39] The results of the remaining 30 unique RCTs that were not 
included in the MACH-NC meta-analysis were reviewed: four tested concurrent CRT [40-43], nine tested taxane-based triplet induction chemotherapy [37, 44-51], 14 investigated anti-EGFR targeted drugs [42, 52-64], two investigated radiosensitizers $[65,66]$, and one studied organ preservation [67].

\section{Outcomes}

\section{Concurrent chemotherapy}

Concurrent addition of chemotherapy to RT was evaluated in three unique RCTs $[40,41,68]$. One RCT examined the addition of twice-weekly concurrent carboplatin added to postoperative RT in 144 patients treated with curative resection who had lymph node metastases [41]. No benefit in locoregional control or overall survival rate was observed.

The MACH-NC meta-analysis suggested improved disease outcomes in LASCCHN with shortened RT treatment time, i.e., accelerated RT [3, 4]. Two RCTs compared standard CRT regimens with accelerated RT plus modified concurrent chemotherapy [40, 43]. Neither RCT detected an incremental benefit of accelerated fraction RT plus chemotherapy compared with conventionally fractionated RT.

As the MACH-NC review did not specifically address the value of concurrent postoperative CRT, and one unique RCT [41] and two MACH-NC RCT updates [11, 29] were identified, a meta-analysis of six RCTs addressing the addition of concurrent chemotherapy to postoperative RT in patients with curatively resected tumours was performed [11, 29, 41, 69-71]. Overall, there was a modest benefit of adding chemotherapy to RT. The hazard ratios of death and locoregional failure were 0.84 (95\% CI, 0.64 to 1.03 ) and 0.57 (95\% CI, 0.45 to 0.71 ), respectively. Benefit was apparent with monoplatinum chemotherapy $(5,6,9,85)$ (HR, 0.78 ; $95 \% \mathrm{CI}, 0.61$ to 0.99 ) but not with non-platinum-based chemotherapy [11, 71] (HR, 0.97; 95\% CI, 0.48 to 1.98). These data confirm the value of monoplatin-based CRT in this setting, and support the generalizability of the MACH$\mathrm{NC}$ data to the subgroup of high-risk patients treated with RT after curative surgical resection Figs. 1 and 2.

\section{Targeted agents and radiosensitizers}

Fourteen RCTs investigated anti-EGFR targeted monoclonal antibodies (MoAbs) added to RT in patients with LASCCHN. Six larger RCTs with more than 100 randomized patients per treatment arm were identified [42, 52, 55, 60, 72, 73]. Bonner et al. compared the addition of weekly cetuximab with concomitant boost accelerated, hyperfractionated, or conventionally fractionated RT in 424 patients with LASCCHN. Cetuximab appeared to improve cancer control and survival rate in patients receiving concomitant boost or hyperfractionated radiotherapy; however, there was heterogeneity of treatment effect within subgroups. The subgroup of patients with oropharynx cancer and those treated with accelerated or hyperfractionated RT appeared to benefit the most. It was unclear whether these benefits were

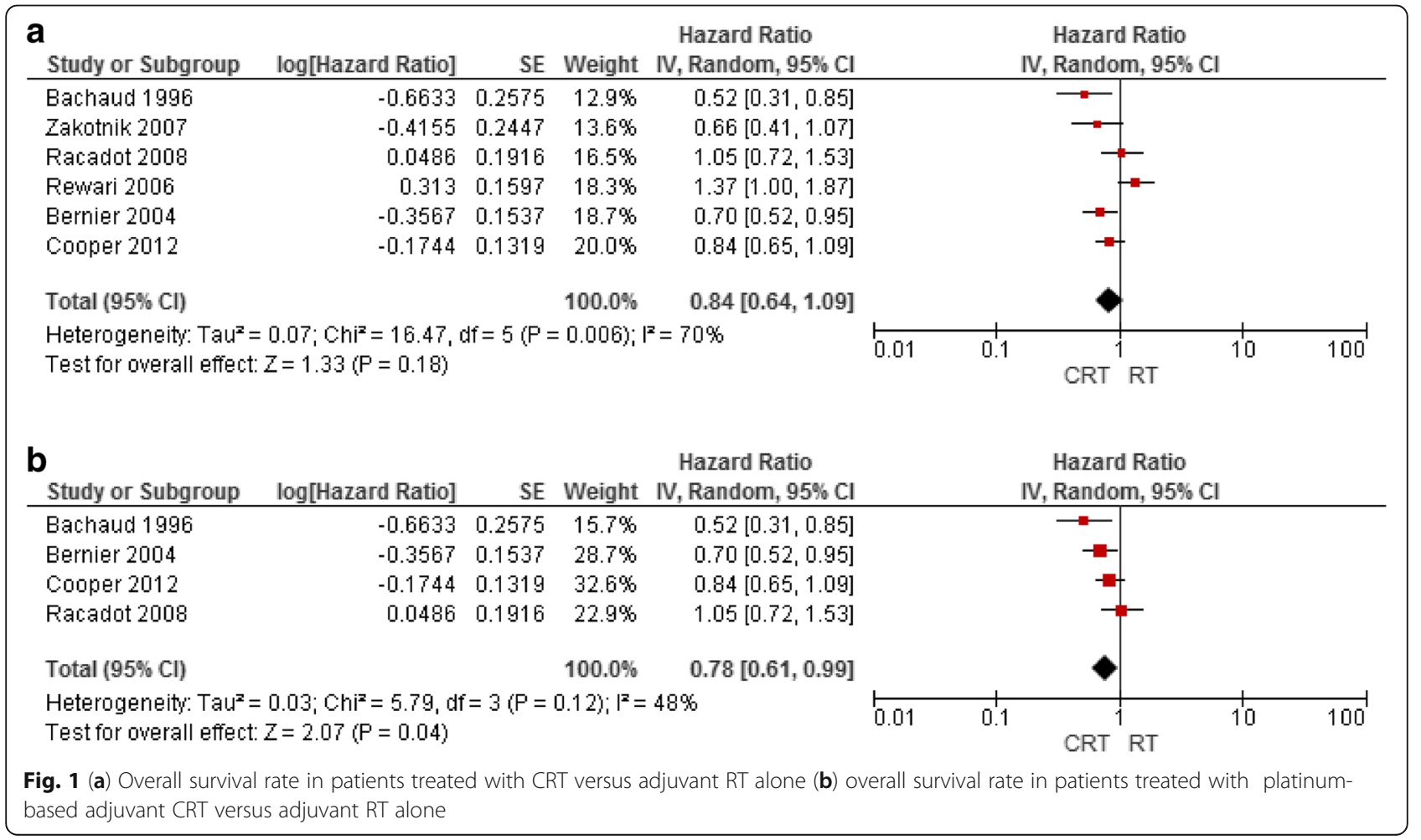




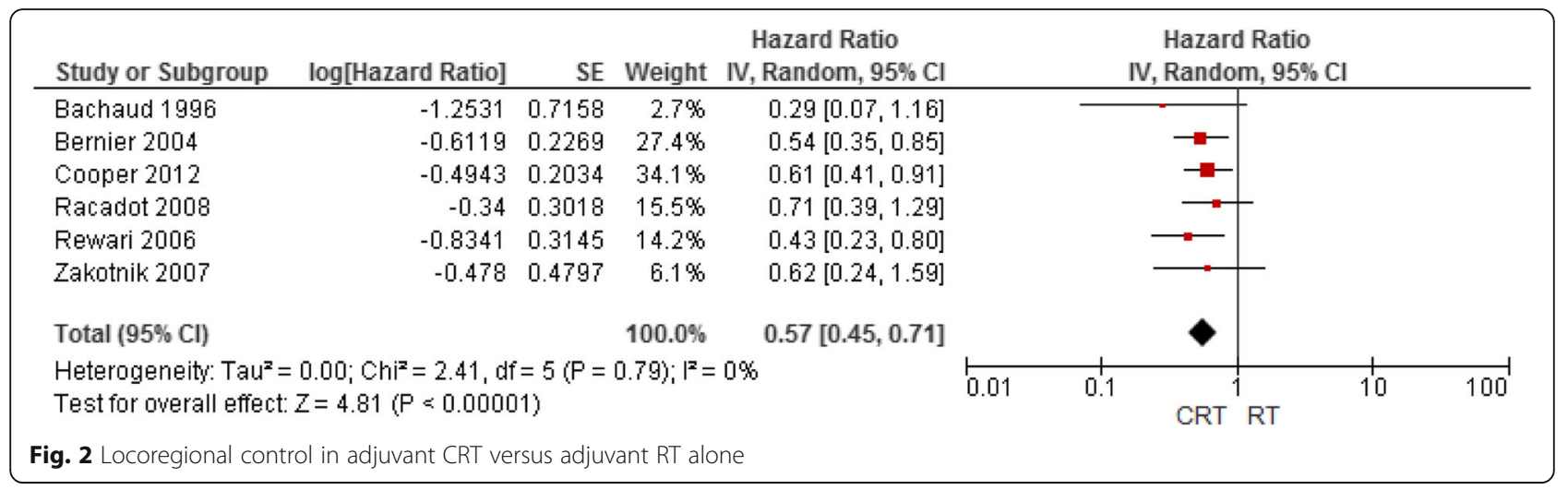

generalizable to patients who had tumours in the larynx or hypopharynx, or were being treated with conventionally fractionated RT; and no confirmatory RCT has been done. The addition of cetuximab increased treatment toxicity compared with RT alone.

Two larger RCTs investigated panitumumab combined with accelerated fraction RT [52, 74] in patients with LASCCHN treated with accelerated fraction RT. Giralt et al. [74] randomized 303 patients to either concurrent panitumumab or two cycles of high-dose cisplatin. PFS demonstrated a benefit favouring cisplatin, with similar trends in locoregional control and overall survival rates. Siu et al. randomized 320 patients to either conventional CRT with high-dose cisplatin (three cycles) or concomitant boost accelerated RT plus panitumumab. No overall or progression-free survival rate benefits were observed, and non-inferiority of the experimental arm was not proven.

Three larger RCTs tested the addition of anti-EGFR MoAb to accelerated fraction CRT [55, 72, 73]. Ang et al. investigated the addition of cetuximab to concomitant boost accelerated RT plus high-dose cisplatin (two cycles) in 891 randomized patients. Adverse effects were increased and there was no improvement in disease outcomes, including overall survival rate. Eriksen et al. investigated the addition of zalutumumab to accelerated fraction RT plus weekly cisplatin and daily nimorazole in 619 randomized patients. No improvements in locoregional control, disease-specific or overall survival rates were observed. Mesia et al. investigated the addition of panitumumab to accelerated fraction RT plus high-dose cisplatin (two cycles) in 303 randomized patients. The cisplatin dose was reduced by $25 \%$ in the panitumumab arm. Disease outcomes were not improved by the addition of panitumumab and rates of AEs were similar.

Zackrisson et al. [75] were unable to identify evidence of overall survival benefit in 5 RCTs of hypoxic radiosensitizers added to RT for LASCCHN reported up to August 2001. Since the review by Zackrisson et al. [76], two unique eligible RCTs studying radiosensitizers were identified $[65,66]$. Rischin et al. [66] investigated the addition of tirapazamine in 861 randomized patients with LASCCHN receiving conventional fractionation RT plus high-dose cisplatin (three cycles). The cisplatin dose was reduced by $25 \%$ in the tirapazamine arm. No improvement in disease outcomes, including overall survival was observed. Metwally et al. [65] investigated nimorazole added to accelerated RT but were only able to enroll 104 patients and were unable to demonstrate overall survival benefit.

\section{Induction chemotherapy}

Overall, the MACH-NC meta-analysis detected no OS benefit of induction chemotherapy compared with local therapy alone (HR, $0.96 ; 95 \% \mathrm{CI}, 0.90$ to $1.02 ; p=0.18$ ); and, in a more recent unique three-arm RCT, Hitt et al. [47] reported no OS benefit with the addition of cisplatin plus 5-fluorouracil (PF) induction to concurrent $\mathrm{CRT}$ in 284 randomized patients. However, the MACH$\mathrm{NC}$ authors did report that treatment with PF-based induction chemotherapy appeared to be associated with a modest overall survival benefit (HR, 0.90; 95\% CI, 0.82 to 0.99 ). This evidence, along with identification of the taxane drugs paclitaxel and docetaxel as active agents in $\mathrm{SCCHN}$, prompted continued interest in investigating induction chemotherapy.

As randomized Phase II trials have not demonstrated a benefit of taxane-cisplatin doublets compared with $\mathrm{PF}$ $[9,17]$ we limited the scope of eligible RCTs to those adding paclitaxel or docetaxel to PF. Nine eligible RCTs were identified. Four RCTs compared taxane-based triplet induction chemotherapy (TPF) with PF induction prior to RT or CRT [37, 48, 50,51]. Meta-analysis of these RCTs detected an overall survival benefit favouring TPF (Fig. 3) but the control arms of these RCTs do not show an overall survival benefit (Fig. 3). However, these comparisons are of value in assessing the objective tumour response rates (ORRs) associated with these two approaches. Meta-analysis demonstrated that TPF is associated with a higher ORR (odds ratio, 1.46; 95\% CI, 1.25 to 1.70). TPF treatment is associated with more neutropenia and risk of neutropenic sepsis than PF, 


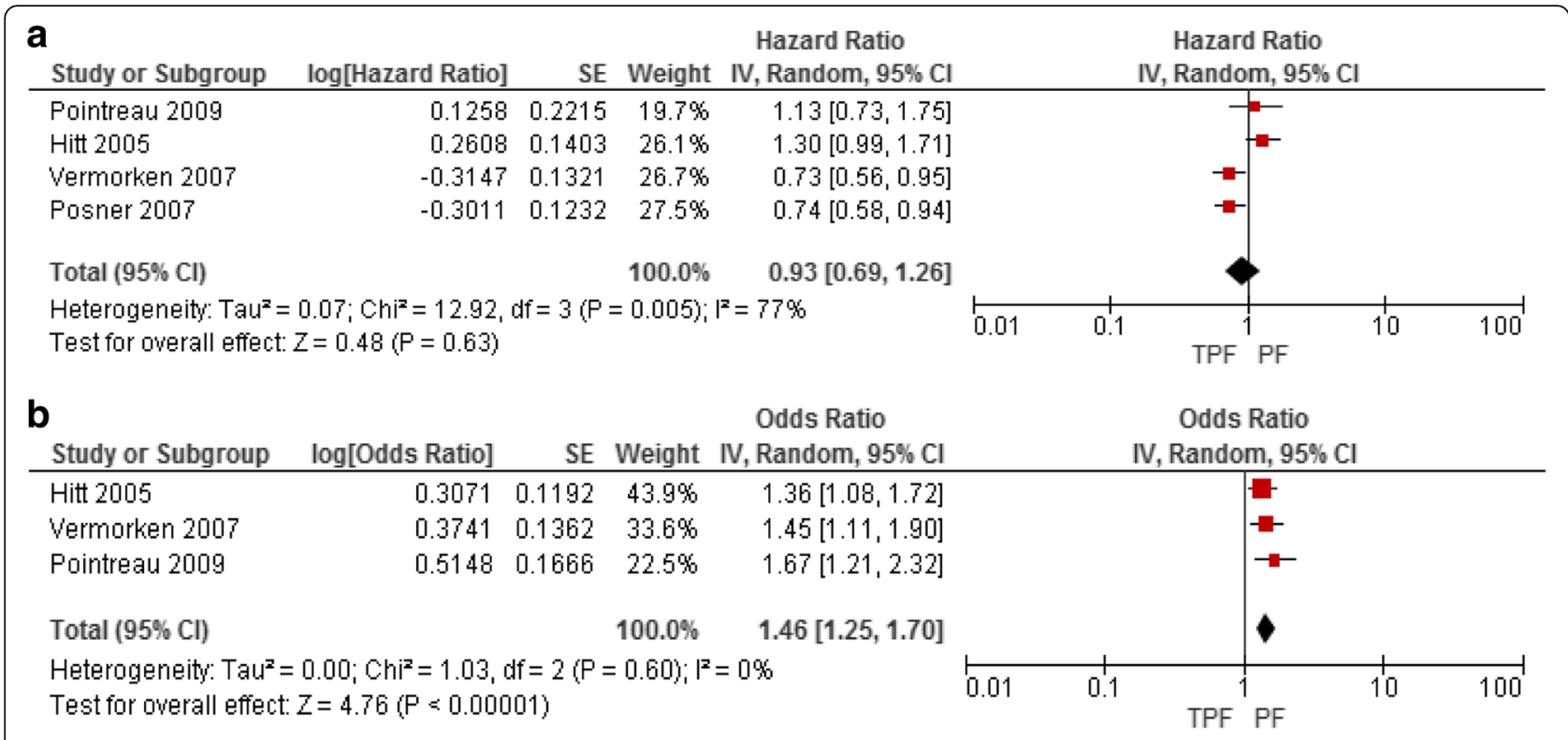

Fig. 3 (a) Overall survival for patients treated with induction TPF versus PF (b) ORR for patients treated with induction TPF versus PF

which could be abrogated with the use of primary granulocyte-colony stimulating factor prophylaxis.

Five RCTs compared TPF induction chemotherapy followed by CRT with CRT alone [44-47, 49]. A meta-analysis of these RCTs (Fig. 4) did not show improvement in OS with induction TPF followed by CRT. However, the three-year overall survival rate in the control arms of two RCTs [46, 49] was more than $75 \%$ and in three RCTs was less than $50 \%$. When the latter three RCTs are meta-analyzed separately OS improvement was still not seen: HR 0.90 (95\% CI 0.68 to 1.19 ).

\section{Larynx preservation}

In patients with LASCCHN of the larynx or hypopharynx that is, potentially curable with radical surgery that requires laryngectomy, primary RT has been used to potentially provide cancer cure while also preserving the larynx and possibly the patient's natural voice. Patients suffering cancer recurrence after RT are then potentially cured with salvage surgery. Two major strategies have been investigated to improve larynx preservation and cure rates in these patients: 1 . concomitant CRT in all patients with salvage surgery at relapse (the preferred approach in Ontario), and 2. induction chemotherapy with choice of subsequent treatment based on tumour response (i.e. patients with at least partial remission are treated with primary RT and nonresponding patients are treated with laryngectomy with or without postoperative $\mathrm{RT})$. The MACH-NC meta-analysis [3] identified three RCTs testing the latter strategy versus laryngectomy and reported a non-significant overall survival rate trend favouring primary surgery.

More recently Denaro et al. [39] provided a critical review of data from nine RCTs studying larynx preservation strategies. Difficulties in comparing trial results due to differing endpoint definitions were identified. Improved larynx preservation was identified, but at the cost of increased adverse effects, with concurrent, alternating,

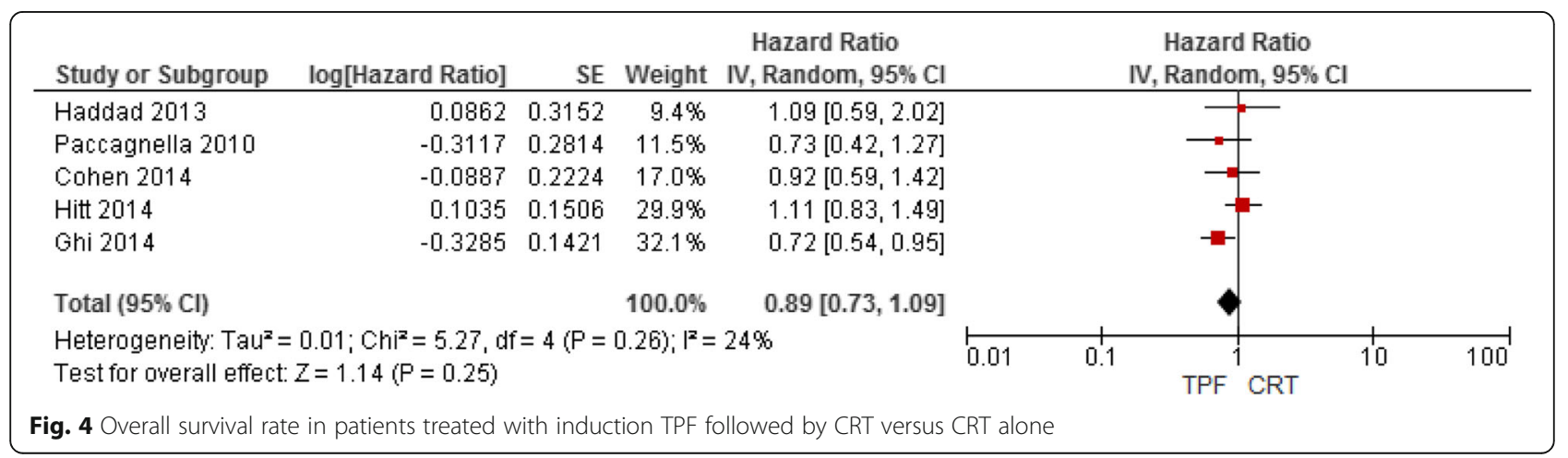


and induction chemotherapy strategies compared with RT alone. An optimal approach could not be recommended. Updated results reported by Forastiere et al. [30] showed similar laryngectomy-free survival rate with CRT and induction chemotherapy but with an overall survival trend favouring induction chemotherapy. An RCT comparing TPF with PF induction chemotherapy for organ preservation appeared to report superior outcomes with TPF; and retrospective analysis of another RCT not designed for organ preservation appeared to support these results [37]. One additional unique RCT evaluating organ preservation was identified. Soo et al. [67] compared primary surgery followed by radiotherapy with CRT in 119 patients with resectable head and neck cancers. The overall organ preservation rate was $45 \%$ with CRT, and organ preservation was higher with larynx and hypopharynx primary tumours. Three-year disease-free survival rates were similar.

\section{Adverse effects and quality of life}

Concurrent chemotherapy Compared to RT alone, more toxic effects were reported in the CRT groups. The rates of late adverse effects were similar between the trial groups but acute adverse effects appeared to be more common in the chemotherapy groups. In the UKHAN1 trial, the incidence of acute adverse effects was doubled compared to RT alone [33]. While hematologic $\mathrm{AE}$ were reportedly very mild, mucositis was the most common non hematologic adverse event reported in these trials. Greater number of CRT patients required enteral or parenteral feeding. In the SAAK study, the incidence of late adverse effects did not differ when cisplatin was added concurrently to hyperfractionated RT. When the addition of chemotherapy to different fractionations of RT was evaluated, patients in the very accelerated RT group had more acute adverse effects compared with patients who were administered conventional or accelerated RT ( $84 \%$ versus $76 \%$ or $69 \%$ ) $p=0.0001$ [40].

Postoperatively, A combined data analysis of the RTOG 9501 and EORTC 22931 trials suggested a differential benefit of CRT over RT alone in subgroups of patients [16]. However the addition of chemotherapy to RT increased the incidence of adverse effects in these trials. A $43 \%(p=0.001)$ difference in the rate of acute toxicity was reported in the RTOG 9501 study [77]. The tendency of developing a Grade 3 adverse effect was higher in the cisplatin arm (78\%) compared to RT alone (46\%); $p=0.001$. Similar results $-41 \%$ in the CT arm against $21 \%$ in the $\mathrm{RT}$ arm $(p=0.001)$ - were reported by Bernier et al. [70]. The three studies that compared postoperative chemotherapy to no treatment also reported no significant difference in adverse effects.
Targeted agent and radio sensitizers Although most of the studies reported a trend towards a higher incidence of $\mathrm{AE}$ in the intervention groups, the differences in the rates of AEs and quality of life (QoL) score between the groups were not significant. In the study reported by Bonner et al. [58], the incidence of Grade 3 to 5 infusion reactions and acneiform rash were was significantly higher in the cetuximab arm, and these adverse effects seemed to occur mainly in the first five to 15 days of treatment. In the trial reported by Ang et al. [55], more treatment-related Grade 5 AEs were reported in the cetuximab arm $(p=0.05)$. The higher rates of Grade 3 to 5 skin reactions and mucositis in the cetuximab arm did not remain significant after 90 days post-therapy, but the feeding tube dependency rate at three years was higher in the cetuximab arm (12\% versus $7 \% ; p=0.05)$. Rodriguez et al. [63] reported that the QoL in patients treated with epidermal growth factor receptor inhibitor (EGFRI) was significantly better in relation to their global health status, while physical, emotional, social, cognitive, and individual symptoms on a general health scale were not different between groups. However, Curran et al. [78] reported better health on a physical function scale in patients in the group treated with an EGFRI.

Induction chemotherapy The most common hematologic AEs observed were myelosuppression, neutropenia, thrombocytopenia, and anemia, while mucositis, fatigue, alopecia, nausea, and dehydration were the common non-hematologic AEs. The rates of hematologic AEs were higher in patients in the induction chemotherapy (IC) group. Among the studies that evaluated the use of IC followed by CRT, one study reported that patients treated with IC before receiving CRT were more likely to develop an $\mathrm{AE}$ compared with those that did not receive IC: $47 \%$ versus 28\%; $p=0.002$ [44]. In the studies that compared TPF with PF regimen, there were no significant differences in the rates of AEs between the arms. However, there were more dose delays in the PF arm than in the TPF arm $(64.8 \%$ versus $10.9 \% ; p<0.001)$ [51]. The need for tracheostomy or dependence on a gastric tube was used as a surrogate measure for long-term adverse effects in one study and there was no difference between the groups [79]. There was a trend for PF regimen to have significantly more thrombocytopenic AEs in the studies, while the incidence of neutropenia and anemia were greater in TPF or other triple regimens. An earlier analysis of the TAX 324 study demonstrated a significantly higher incidence of Grade 3/4 neutropenia in the use of TPF compared with PF (83\% versus $56 \%$; $p=0.001$ ) [50]. 


\section{Discussion}

Squamous cell carcinoma is the predominant mucosal cancer of the head and neck region. Previously untreated patients with locally advanced disease have high rates of tumour shrinkage with chemotherapy, and this has prompted studies involving multimodality treatment schedules, including induction, adjuvant, alternating, and concurrent chemotherapy treatment. More recently targeted agents and radiosensitizers have also been studied. This overview was undertaken to review and pool the existing evidence and derive a consensus around the role of systemic therapies in the management of patients with locally advanced SCCHN. Although the incidence of SCCHN has been on the rise, with overwhelming evidence in support of HPV as an important reason for the increase, this was historically unknown. RCTs studying chemotherapy did not stratify randomization or adjustresults based on tumour HPV status. This is important in consider in both the interpretation and generalizability of their results..Despite this, in subgroup analyses the MACH-NC did show similar benefits of concomitant chemotherapy in oropharynx cancers compared to the other head and neck cancer subsites [4].

The role of chemotherapy is most clear for its concomitant use with postoperative or radical radiation therapy (RT). The MACH-NC meta-analysis identified benefits in overall survival with this approach more than a decade ago, and the use of concomitant chemotherapy with RT (mainly concurrently in the Ontario setting [CRT]) is recognized as a standard of care. This benefit was more profound with platinum-based chemotherapy, and the most robust evidence is for cisplatin. High-dose cisplatin $100 \mathrm{mg} / \mathrm{m}^{2}$ IV days 1,22 and 43 of RT was most commonly studied. However, alternative cisplatin schedules may be quite reasonable, and in our review of these RCTs it seemed clear that some dose effect was present supporting optimal doses of at least $40 \mathrm{mg} / \mathrm{m}^{2}$ per week. A schedule of cisplatin $40 \mathrm{mg} / \mathrm{m} 2$ IV weekly during RT is used as a standard approach for cervical cancer and has been adopted as a standard arm for clinical trials by the NRG clinical trials group. Data for carboplatin was conflicting and its routine use in CRT cannot be endorsed. There was less data supporting use of 5-FU plus platin with CRT, however, the Calais regimen (carboplatin $70 \mathrm{mg} / \mathrm{m}^{2}$ bolus plus continuous infusion 5 -FU $600 \mathrm{mg} / \mathrm{m}^{2}$ each IV daily for 4 days weeks 1 and 4 of RT) is a reasonable alternative for patients unsuitable for cisplatin. This regimen should be used with caution as carboplatin dosing is not based on renal function which may become compromised as a consequence of orpharyngeal mucositis during treatment.

Of targeted agents and radiosensitizers studied in RCTs as alternatives or additions to CRT, only the anti-EGFR monoclonal antibody cetuximab has shown benefit. However, although the addition of cetuximab to RT was shown superior to RT alone, not RCTs have yet demonstrated superiority or non-inferiority of cetuximab-RT to CRT. In view of this, and the voluminous evidence supporting CRT, cetuximab-RT can only be considered a standard option for treatment in patients who are not candidates for the chemotherapy used with CRT.

Induction chemotherapy remains a controversial topic. Superior outcomes were reported in RCTs comparing induction TPF to PF prior to local therapy, including overall survival and larynx preservation. However, RCTs comparing TPF followed by CRT to CRT alone have shown mainly negative results. In part this may reflect testing of more aggressive and toxic therapy in patient populations enriched with HPV-related cancers which have an intrinsically good prognosis with CRT. Induction chemotherapy does remain useful for rapid tumour downsizing for symptom relief prior to definitive local therapy, and in this regard TPF does appear to have a superior response rate to PF chemotherapy. TPF chemotherapy should be used by experienced medical oncologists, and its increased myelosuppressive effects may be abrogated by primary prophylaxis with G-CSF. Longterm results of the RTOG 9111 RCT are also provocative in identifying a possible role for induction chemotherapy in larynx preservation. PF chemotherapy was associated with similar laryngectomy progression-free survival and a trend to better overall survival compared with CRT. As TPF has been shown superior to PF in such a setting, further investigation of induction approaches for larynx preservation may be warranted.

\section{Conclusions}

Locally advanced squamous cell carcinoma of the head and neck cancer is a lethal disease left untreated, and can have devastating effects on quality of life as a consequence of treatment. The addition of systemic chemotherapy concurrently with radical or postoperative adjuvant radiation therapy remains a standard albeit potentially toxic treatment approach for appropriate patients. The role for induction treatment beyond tumour downsizing and symptom relief prior to local therapy remains controversial. Induction chemotherapy for improving larynx preservation and survival in larynx and hypopharynx cancer may be an alternative to CRT, and triplet regimens incorporating docetaxel are of interest in this domain. There is proof of principle that concurrent cetuximab-RT is superior to RT alone, but it is unclear whether cetuximab-RT can be considered non-inferior to CRT. Evidence form RCTs studying patients with LASCCHN continues to accumulate. It is expected that clearer guidance will emerge from these in future in the realms of HPV-related cancers, the 
use of targeted therapy, and use of induction chemotherapy which will inform future guideline recommendations.

\section{Abbreviations}

AE: Adverse Event; AMSTAR: Assessment of Multiple Systematic Reviews; ASCO: American Society of Clinical Oncology; ASTRO: American Society for Radiation Oncology; CCO: Cancer Care Ontario; Cl: Confidence interval; CRT: Concurrent chemoradiotherapy; DFS: Disease free survival rate; DSG: Disease Cancer Site Group; ECOG: Eastern Cooperative Oncology Group; EGFR: Epidermal growth factor receptor; ESMO: European Society for Medical Oncology; ESTRO: European Society for Therapeutic Radiation and Oncology; HPV: Human papillomavirus; HR: Hazard Ratios; LASCCHN: Locally advanced Squamous cell carcinoma of the head and neck; MACH-NC: Meta-analysis of chemotherapy in head and neck cancer; MoAbs: Monoclonal antibodies; OS: Overall survival rate; PEBC: Program in Evidence-based Care; QoL: Quality of life; RCT: Randomized Controlled trials; RT: Radiotherapy; SCCHN: Squamous cell carcinoma of the head and neck; WHO: World Health Organization

\section{Acknowledgements}

The Head and Neck Cancer DSG and the Working Group would like to thank the following individuals for their assistance in developing this report: Fulvia Baldassarre, Bill Evans, Glenn Fletcher, Aaron Hansen, Melissa Brouwers, Donna E. Maziak, Sheila McNair, Hans Messersmith, Jan Vermorken, Michael Vickers, for providing feedback on draft versions; Elizabeth Chan for conducting a data audit; Janet Rowe for copy editing.

\section{Funding}

The PEBC is a provincial initiative of CCO supported by the Ontario Ministry of Health and Long-Term Care (OMHLTC). All work produced by the PEBC and any associated programs is editorially independent from the OMHLTC.

\section{Availability of data and materials}

All data analysed during this study is from the referenced articles.

\section{Authors' contributions}

All authors contributed in the drafting and reviewing feedbacks on the drafts. All authors have read and approved the final manuscript. EW and CA drafted.

\section{Competing interests}

EW declared being a local principal investigator for HN.6 trial, TAX 324 trial and NCIC HN.6 trial. JY declared having Stocks, bonds, or stock options valued at $\$ 5,000$ or more in a relevant business entity that may not necessarily gain or lose financially from the publication of the manuscript, either now or in the future. The other authors declare no competing interests.

\section{Consent for publication}

Not applicable.

\section{Ethics approval and consent to participate}

Not applicable.

\section{Publisher's Note}

Springer Nature remains neutral with regard to jurisdictional claims in published maps and institutional affiliations.

\footnotetext{
Author details

'Department of Oncology, Western University and London Health Science Centre, 790 Commissioners Rd East, PO Box 5010 London, Ontario N6A 5W9 London, Ontario, Canada. ${ }^{2}$ Department of Otolaryngology-Head and Neck Surgery, Western University and London Health Sciences Centre, London, ON, Canada. ${ }^{3}$ Department of Oncology, McMaster University, Juravinski Cancer Centre, 699 Concession Street, Hamilton, ON L8V 5C2, Canada. ${ }^{4}$ Sunnybrook Odette Cancer Centre, Toronto, ON, Canada. ${ }^{5}$ Department of Oncology, McMaster University (Juravinski Hospital Site), 1280 main Street West, Hamilton, ON L8S 4L8, Canada.
}

Received: 26 October 2016 Accepted: 13 March 2017 Published online: 04 April 2017

\section{References}

1. Schiff BA. Overview of Head and Neck Tumors - Tumors of the Head and Neck Merck Manual Professional Version. Retrieved from http://www. merckmanuals.com/en-ca/professional/ear,-nose,-andthroat-disorders/ tumors-of-the-head-and-neck/overview-of-head-and-neck-tumors.

2. Ma J, Liu Y, Yang X, Zhang CP, Zhang ZY, Zhong LP. Induction chemotherapy in patients with resectable head and neck squamous cell carcinoma: a meta-analysis. World J Surg Oncol. 2013;11:67.

3. Pignon JP, Bourhis J, Domenge C, Designe L. Chemotherapy added to locoregional treatment for head and neck squamous-cell carcinoma: three meta-analyses of updated individual data. MACH-NC Collaborative Group. Meta-Analysis of Chemotherapy on Head and Neck Cancer. Lancet. 2000;355(9208):949-55.

4. Pignon JP, Maitre A, Maillard E, Bourhis J. Meta-analysis of chemotherapy in head and neck cancer (MACH-NC): An update on 93 randomised trials and 17,346 patients. Radiother Oncol. 2009;92(1):4-14.

5. Shea BGJ, Wells G, Boers M, Andersson N, Hamel C, et al. Development of AMSTAR: a measurement tool to assess the methodological quality of systematic reviews. BMC Med Res Method. 2007;7:10.

6. Blanchard P, Baujat B, Holostenco V, Bourredjem A, Baey C, Bourhis J, et al. Meta-analysis of chemotherapy in head and neck cancer (MACH-NC): a comprehensive analysis by tumour site. Radiother Oncol. 2011;100(1):33-40.

7. Review Manager (RevMan) [Computer program]. Version 5.3 Copenhagen: The Nordic Cochrane Centre, The Cochrane Collaboration. 2014.

8. Parmar MK, Tori V, Stewart L. Extracting summary statistics to perform metaanalyses of the published literature for survival endpoints: [erratum appears in Stat Med. Stat Med. 2004;17(24):2815-34.

9. Chen H, Zhou L, Chen D, Luo J. Clinical efficacy of neoadjuvant chemotherapy with platinum-based regimen for patients with locoregionally advanced head and neck squamous cell carcinoma: an evidence-based meta-analysis. Ann Saudi Med. 2011;31(5):502-12.

10. Petrelli F, Barni S. Anti-EGFR-targeting agents in recurrent or metastatic head and neck carcinoma: a meta-analysis. Head Neck. 2012;34(11):1657-64.

11. Rewari AN, Haffty BG, Wilson LD, Son YH, Joe JK, Ross DA, et al. Postoperative concurrent chemoradiotherapy with mitomycin in advanced squamous cell carcinoma of the head and neck: results from three prospective randomized trials. Cancer J. 2006;12(2):123-9.

12. Su YX, Zheng JW, Zheng GS, Liao GQ, Zhang ZY. Neoadjuvant chemotherapy of cisplatin and fluorouracil regimen in head and neck squamous cell carcinoma: a meta-analysis. Chin Med J. 2008;121(19):1939-44.

13. Zhang S, Chen J, Jiang H, Ma H, Yang B. Anti-epidermal growth factor receptor therapy for advanced head and neck squamous cell carcinoma: a meta-analysis. Eur J Clin Pharmacol. 2012;68(5):561-9.

14. Budach W, Hehr T, Budach V, Belka C, Dietz K. A meta-analysis of hyperfractionated and accelerated radiotherapy and combined chemotherapy and radiotherapy regimens in unresected locally advanced squamous cell carcinoma of the head and neck. BMC Cancer. 2006;6:28.

15. Furness S, Glenny AM, Worthington HV, Pavitt S, Oliver R, Clarkson JE, et al. Interventions for the treatment of oral cavity and oropharyngeal cancer: chemotherapy. Cochrane Database Syst Rev. 2011;4:CD006386.

16. Bernier J, Cooper JS, Pajak TF, van Glabbeke M, Bourhis J, Forastiere A, et al. Defining risk levels in locally advanced head and neck cancers: a comparative analysis of concurrent postoperative radiation plus chemotherapy trials of the EORTC (\#22931) and RTOG (\# 9501). Head Neck. 2005;27(10):843-50.

17. Fonseca E, Grau JJ, Sastre J, Garcia-Gomez JM, Rueda A, Pastor M, et al. Induction chemotherapy with cisplatin/docetaxel versus cisplatin/5fluorouracil for locally advanced squamous cell carcinoma of the head and neck: a randomised phase II study. Eur J Cancer. 2005;41(9):1254-60.

18. Koh Y, Lee KW, Kim SB, Park KH, Shin SW, Kang JH, et al. A randomized, multicenter, open phase II study of cetuximab with docetaxel, cisplatin as induction chemotherapy in unresectable, locally advanced head and neck squamous cell carcinoma (LA-HNSCC). J Clin Oncol. 2013;31(15_suppl).

19. Rivera F, Vega-Villegas ME, Lopez-Brea M, Isla D, Mayorga M, Galdos P, et al. Randomized phase II study of cisplatin and 5-FU continuous infusion (PF) versus cisplatin, UFT and vinorelbine (UFTVP) as induction chemotherapy in locally advanced squamous cell head and neck cancer (LA-SCHNC). Cancer Chemother Pharmacol. 2008;62(2):253-61. 
20. Seiwert TY, Haraf DJ, Cohen EE, Blair EA, Stenson K, Salama JK, et al. A randomized phase II trial of cetuximab-based induction chemotherapy followed by concurrent cetuximab, 5-FU, hydroxyurea, and hyperfractionated radiation (CetuxFHX), or cetuximab, cisplatin, and accelerated radiation with concomitant boost (CetuxPX) in patients with locoregionally advanced head and neck cancer (HNC). J Clin Oncol. 2011;29(15_suppl).

21. Chauhan A, Singh H, Sharma T, Manocha KK. Gemcitabine concurrent with radiation therapy for locally advanced head and neck carcinomas. Afr Health Sci. 2008;8(3):149-55.

22. Halim AA, Wahba HA, El-Hadaad HA, Abo-Elyazeed A. Concomitant chemoradiotherapy using low-dose weekly gemcitabine versus low-dose weekly paclitaxel in locally advanced head and neck squamous cell carcinoma: a phase III study. Med Oncol. 2012;29(1):279-84.

23. Harari PM, Harris J, Kies MS, Myers JN, Jordan RC, Gillison ML, et al. Postoperative chemoradiotherapy and cetuximab for high-risk squamous cell carcinoma of the head and neck: Radiation Therapy Oncology Group RTOG-0234. J Clin Oncol. 2014:32(23):2486-95.

24. Taguchi T, Kubota A, Yoshino K, Tomita K, Kohno N, Kawabata K, et al. Adjuvant chemotherapy with S-1 after curative treatment in patients with head and neck cancer (ACTS-HNC). J Clin Oncol. 2013;31(15_suppl).

25. Lam P, Yuen APW, Ho CM, Ho WK, Wei WI. Prospective randomized study of post-operative chemotherapy with levamisole and UFT for head and neck carcinoma. Eur J Surg Oncol. 2001;27(8):750-3.

26. Mesia R, Rueda A, Vera R, Lozano A, Medina JA, Aguiar D, et al. Adjuvant therapy with cetuximab for locally advanced squamous cell carcinoma of the oropharynx: results from a randomized, phase II prospective trial. Ann Oncol. 2013;24(2):448-53.

27. Rischin D, Peters L, Fisher R, Macann A, Denham J, Poulsen M, et al. Tirapazamine, cisplatin, and radiation versus fluorouracil, cisplatin, and radiation in patients with locally advanced head and neck cancer: a randomized phase II trial of the Trans-Tasman radiation Oncology Group (TROG 98.02). J Clin Oncol. 2005;23(1):79-87.

28. Domenge $C$, Hill C, Lefebvre $J$, De Raucourt D, Rhein B, Wibault $P$, et al. Randomized trial of neoadjuvant chemotherapy in oropharyngeal carcinoma. Br J Cancer. 2000;83(12):1594-8.

29. Cooper JS, Zhang Q, Pajak TF, Forastiere AA, Jacobs J, Saxman SB, et al. Long-term follow-up of the RTOG 9501/intergroup phase III trial: postoperative concurrent radiation therapy and chemotherapy in high-risk squamous cell carcinoma of the head and neck. Int J Radiat Oncol Biol Phys. 2012;84(5):1198-205.

30. Forastiere AA, Zhang Q, Weber RS, Maor MH, Goepfert H, Pajak TF, et al. Long-term results of RTOG 91-11: a comparison of three nonsurgical treatment strategies to preserve the larynx in patients with locally advanced larynx cancer. J Clin Oncol. 2013;31(7):845-52.

31. Haffty BG, Wilson LD, Son YH, Cho El, Papac RJ, Fischer DB, et al. Concurrent chemo-radiotherapy with mitomycin C compared with porfiromycin in squamous cell cancer of the head and neck: final results of a randomized clinical trial. Int J Radiat Oncol Biol Phys. 2005;61(1):119-28.

32. Quon H, Leong T, Haselow R, Leipzig B, Cooper J, Forastiere A. Phase III study of radiation therapy with or without cis-platinum in patients with unresectable squamous or undifferentiated carcinoma of the head and neck: an intergroup trial of the Eastern Cooperative Oncology Group (E2382). Int J Radiat Oncol Biol Phys. 2011;81(3):719-25.

33. Tobias JS, Monson K, Gupta N, MacDougall H, Glaholm J, Hutchison I, et al. Chemoradiotherapy for locally advanced head and neck cancer: 10-year followup of the UK Head and Neck (UKHAN1) trial. Lancet Oncol. 2010;11(1):66-74.

34. Ghadjar P, Simcock M, Studer G, Allal AS, Ozsahin M, Bernier J, et al. Concomitant cisplatin and hyperfractionated radiotherapy in locally advanced head and neck cancer: 10-year follow-up of a randomized phase III trial (SAKK 10/94). Int J Radiat Oncol Biol Phys. 2012;82(2):524-31.

35. Forastiere AA, Goepfert H, Maor M, Pajak TF, Weber R, Morrison W, et al. Concurrent chemotherapy and radiotherapy for organ preservation in advanced laryngeal cancer. N Engl J Med. 2003;349(22):2091-8.

36. Lefebvre $L$, Rolland F, Tesselaar M, Bardet E, Leemans CR, Geoffrois L, et al. Phase 3 randomized trial on larynx preservation comparing sequential vs alternating chemotherapy and radiotherapy. J Natl Cancer Inst. 2009;101(3):142-52.

37. Yoann P, Pascal G, Sophie C, Christian S, Claude T, Jacques T, et al. Randomized trial of induction chemotherapy with cisplatin and 5fluorouracil with or without docetaxel for larynx preservation. J Natl Cancer Inst. 2009;101(7):498-506.

38. Posner MR, Norris CM, Wirth LJ, Shin DM, Cullen KJ, Winquist EW, et al Sequential therapy for the locally advanced larynx and hypopharynx cancer subgroup in TAX 324: survival, surgery, and organ preservation. Ann Oncol. 2009;20(5):921-7.

39. Denaro N, Russi EG, Lefebvre JL, Merlano MC. A systematic review of current and emerging approaches in the field of larynx preservation. Radiother Oncol. 2014;110(1):16-24.

40. Bourhis J, Sire C, Graff P, Gregoire V, Maingon P, Calais G, et al. Concomitant chemoradiotherapy versus acceleration of radiotherapy with or without concomitant chemotherapy in locally advanced head and neck carcinoma (GORTEC 99-02): an open-label phase 3 randomised trial. Lancet Oncol. 2012;13(2):145-53.

41. Racadot S, Mercier M, Dussart S, Dessard-Diana B, Bensadoun RJ, Martin M, et al. Randomized clinical trial of post-operative radiotherapy versus concomitant carboplatin and radiotherapy for head and neck cancers with lymph node involvement. Radiother Oncol. 2008;87(2):164-72.

42. Bonner JA, Harari PM, Giralt J, Cohen RB, Jones CU, Sur RK, et al. Radiotherapy plus cetuximab for locoregionally advanced head and neck cancer: 5-year survival data from a phase 3 randomised trial, and relation between cetuximab-induced rash and survival.[Erratum appears in Lancet Oncol. 2010 Jan;11(1):14]. Lancet Oncol. 2010;11(1):21-8.

43. Nguyen-Tan PF, Zhang Q, Ang KK, Weber RS, Rosenthal DI, Soulieres D, et al Randomized phase III trial to test accelerated versus standard fractionation in combination with concurrent cisplatin for head and neck carcinomas in the Radiation Therapy Oncology Group 0129 trial: long-term report of efficacy and toxicity. J Clin Oncol. 2014;32(34):3858-66.

44. Cohen EE, Karrison TG, Kocherginsky M, Mueller J, Egan R, Huang CH, et al. Phase III randomized trial of induction chemotherapy in patients with N2 or N3 locally advanced head and neck cancer. J Clin Oncol. 2014;32(25):2735-43.

45. Ghi MG, Paccagnella A, Ferrari D, Foa P, Rocca MC, Verri E, et al. Concomitant chemoradiation (CRT) or cetuximab/RT (CET/RT) versus induction Docetaxel/ Cisplatin/5-Fluorouracil (TPF) followed by CRT or CET/RT in patients with Locally Advanced Squamous Cell Carcinoma of Head and Neck (LASCCHN). A randomized phase III factorial study (NCT01086826). J Clin Oncol. 2014;32(15_suppl).

46. Haddad R, O'Neill A, Rabinowits G, Tishler R, Khuri F, Adkins D, et al. Induction chemotherapy followed by concurrent chemoradiotherapy (sequential chemoradiotherapy) versus concurrent chemoradiotherapy alone in locally advanced head and neck cancer (PARADIGM): A randomised phase 3 trial. Lancet Oncol. 2013;14(3):257-64.

47. Hitt R, Grau JJ, Lopez-Pousa A, Berrocal A, Garcia-Giron C, Irigoyen A, et al. A randomized phase III trial comparing induction chemotherapy followed by chemoradiotherapy versus chemoradiotherapy alone as treatment of unresectable head and neck cancer. Ann Oncol. 2014;25(1):216-25.

48. Hitt R, Lopez-Pousa A, Martinez-Trufero J, Escrig V, Carles J, Rizo A, et al. Phase III study comparing cisplatin plus fluorouracil to paclitaxel, cisplatin, and fluorouracil induction chemotherapy followed by chemoradiotherapy in locally advanced head and neck cancer. J Clin Oncol. 2005;23(34):8636-45.

49. Paccagnella A, Ghi MG, Loreggian L, Buffoli A, Koussis H, Mione CA, et al. Concomitant chemoradiotherapy versus induction docetaxel, cisplatin and 5 fluorouracil (TPF) followed by concomitant chemoradiotherapy in locally advanced head and neck cancer: a phase II randomized study. Ann Oncol. 2010;21(7):1515-22.

50. Posner MR, Hershock DM, Blajman CR, Mickiewicz E, Winquist $E$, Gorbounova V, et al. Cisplatin and fluorouracil alone or with docetaxel in head and neck cancer. N Engl J Med. 2007;357(17):1705-15.

51. Vermorken JB, Remenar E, van Herpen C, Gorlia T, Mesia R, Degardin M, et al. Cisplatin, fluorouracil, and docetaxel in unresectable head and neck cancer. N Engl J Med. 2007;357(17):1695-704.

52. Siu LL, Waldron JN, Chen BE, Winquist E, Wright JR, Nabid A, et al. Phase III randomized trial of standard fractionation radiotherapy (SFX) with concurrent cisplatin (CIS) versus accelerated fractionation radiotherapy (AFX) with panitumumab (PMab) in patients (pts) with locoregionally advanced squamous cell carcinoma of the head and neck (LA-SCCHN): NCIC Clinical Trials Group HN. 6 trial. ASCO Annual Meeting Proceedings. 2015;33(15_suppl):6000.

53. Ramakrishnan MS, Eswaraiah A, Crombet T, Piedra P, Saurez G, lyer H, et al. Nimotuzumab, a promising therapeutic monoclonal for treatment of tumors of epithelial origin. MAbs. 2009;1(1):41-8.

54. Al Saleh K, Safwat R, Bedair A, El-Sherify M, Shete J, Basmy AAL. Phase II/III randomized study of hyperfractionated radiotherapy with concomitant cetuximab versus concomitant platinum-based chemotherapy in advanced non-metastatic head and neck cancer: Update. J Clin Oncol. 2014;32(15_suppl). 
55. Ang KK, Zhang Q, Rosenthal DI, Nguyen-Tan PF, Sherman EJ, Weber RS, et al. Randomized phase III trial of concurrent accelerated radiation plus cisplatin with or without cetuximab for stage III to IV head and neck carcinoma: RTOG 0522. J Clin Oncol. 2014;32(27):2940-50.

56. Bhatnagar AR, Singh DP. A comparative study of a monoclonal antibody against EGFR (nimotuzumab) used in combination with chemoradiation versus chemoradiation alone in the treatment of locally advanced inoperable squamous cell carcinoma of the head and neck. ASCO Meeting Abstracts. 2012;30(30_suppl):51.

57. Bhattacharya B, Pal S, Chattopadhyay B, Adhikary SS, Basu J, Ghosh T. A prospective randomised controlled trial of concurrent chemoradiation versus concurrent chemoradiation along with gefitinib in locally advanced squamous cell carcinoma of head and neck. Clin Cancer Investig J. 2014;3(2):146-52.

58. Bonner JA, Harari PM, Giralt J, Azarnia N, Shin DM, Cohen RB, et al. Radiotherapy plus cetuximab for squamous-cell carcinoma of the head and neck. N Engl J Med. 2006;354(6):567-78.

59. Giralt J, Fortin A, Mesia R, Minn H, Henke M, Ancona AY, et al. A phase II, randomized trial (CONCERT-1) of chemoradiotherapy (CRT) with or without panitumumab (pmab) in patients (pts) with unresected, locally advanced squamous cell carcinoma of the head and neck (LASCCHN). J Clin Oncol. 2012;30(15_suppl).

60. Giralt J, Trigo JM, Nuyts S, Ozsahin EM, Skladowski K, Hatoum G, et al. Phase 2, randomized trial (CONCERT-2) of panitumumab (PMAD) plus radiotherapy (PRT) compared with chemoradiotherapy (CRT) in patients (PTS) with unresected, locally advanced squamous cell carcinoma of the head and neck (LASCCHN). Ann Oncol. 2012;23(334):1609-618.

61. Harrington K, Berrier A, Robinson M, Remenar E, Housset M, de Mendoza $\mathrm{FH}$, et al. Randomised Phase II study of oral lapatinib combined with chemoradiotherapy in patients with advanced squamous cell carcinoma of the head and neck: rationale for future randomised trials in human papilloma virus-negative disease. Eur J Cancer. 2013;49(7):1609-18.

62. Reddy BKM, Lokesh V, Vidyasagar MS, Shenoy K, Babu KG, Shenoy A, et al. Nimotuzumab provides survival benefit to patients with inoperable advanced squamous cell carcinoma of the head and neck: a randomized, open-label, phase Illb, 5-year study in Indian patients. Oral Oncol. 2014;50(5):498-505.

63. Rodriguez MO, Rivero TC, Bahi RDC, Muchuli CR, Bilbao MA, Vinageras EN, et al. Nimotuzumab plus radiotherapy for unresectable squamous-cell carcinoma of the head and neck. Cancer Biol Ther. 2010;9(5):343-9.

64. Singh PK, Dixit AK, Prashad SN, Saxena T, Shahoo DP, Sharma D. A randomized trial comparing radiotherapy alone versus radiotherapy with Geftinib in locally advance oral cavity cancer. Clin Cancer Investig J. 2013;2(1):29-33.

65. Hassan Metwally MA, Jansen JA, Overgaard J. Study of the Population Pharmacokinetic Characteristics of Nimorazole in Head and Neck Cancer Patients Treated in the DAHANCA-5 Trial. Clin Oncol. 2015;27(3):168-75.

66. Rischin D, Peters LJ, O'Sullivan B, Giralt J, Fisher R, Yuen K, et al. Tirapazamine, cisplatin, and radiation versus cisplatin and radiation for advanced squamous cell carcinoma of the head and neck (TROG 02.02, HeadSTART): a phase III trial of the Trans-Tasman Radiation Oncology Group. J Clin Oncol. 2010;28(18):2989-95.

67. Soo KC, Tan EH, Wee J, Lim D, Tai BC, Khoo ML, et al. Surgery and adjuvant radiotherapy vs concurrent chemoradiotherapy in stage III/IV nonmetastatic squamous cell head and neck cancer: a randomised comparison. $\mathrm{Br} J$ Cancer. 2005;93(3):279-86.

68. Greskovich JF, Gordian M, Koyfman SA, Lorenz R, Scharpf J, Khan M, et al. Improving healthcare value in patients with stage III-IV squamous cell carcinoma of head and neck (HNSCC): Cost and outcome comparison of 2 arms of a randomized, phase 3 trial of definitive chemoradiation (chemoRT). International Journal of Radiation Oncology Biology Physics. 2013;87(2):S501.

69. Bachaud J-M, Cohen-Jonathan E, Alzieu C, David J-M, Serrano E, DalySchveitzer N. Combined postoperative radiotherapy and Weekly Cisplatin infusion for locally advanced head and neck carcinoma: Final report of a randomized trial. Int J Radiat Oncol Biol Phys. 1996;36(5):999-1004.

70. Bernier J, Domenge C, Ozsahin M, Matuszewska K, Lefebvre JL, Greiner RH, et al. Postoperative irradiation with or without concomitant chemotherapy for locally advanced head and neck cancer. N Engl J Med. 2004;350(19):1945-52.

71. Zakotnik B, Budihna M, Smid L, Soba E, Strojan P, Fajdiga I, et al. Patterns of failure in patients with locally advanced head and neck cancer treated postoperatively with irradiation or concomitant irradiation with Mitomycin C and Bleomycin. Int J Radiat Oncol Biol Phys. 2007;67(3):685-90.
72. Eriksen JG, Maare C, Johansen J, Primdahl H, Evensen JF, Kristensen CA, et al. Evaluation of the EGFR-Inhibitor zalutumumab given with primary curative (CHEMO) radiation therapy to patients with squamous cell carcinoma of the head and neck: Results of the DAHANCA 19 randomized phase 3 trial. Int J Radiat Oncol Biol Phys. 2014;88(2):465.

73. Mesia R, Garcia Saenz JA, Lozano A, Pastor M, Grau JJ, Martinez Trufero J, et al. Phase II study with conventional radiotherapy (RT) + cetuximab in patients with advanced larynx cancer who responded to induction chemotherapy (IC): An organ preservation TTCC study. J Clin Oncol (Meeting Abstracts). 2015;33(15_suppl):6037.

74. Giralt J, Trigo J, Nuyts S, Ozsahin M, Skladowski K, Hatoum G, et al. Panitumumab plus radiotherapy versus chemoradiotherapy in patients with unresected, locally advanced squamous-cell carcinoma of the head and neck (CONCERT-2): a randomised, controlled, open-label phase 2 trial. Lancet Oncol. 2015;16(2):221-32.

75. Zackrisson B, Nilsson P, Kjellen E, Johansson KA, Modig H, Brun E, et al. Two-year results from a Swedish study on conventional versus accelerated radiotherapy in head and neck squamous cell carcinoma-the ARTSCAN study. Radiother Oncol. 2011;100(1):41-8.

76. Zackrisson B, Mercke C, Strander H, Wennerberg J, Cavallin-Ståhl E. A systematic overview of radiation therapy effects in head and neck cancer. Acta Oncol. 2003;42(5-6):443-61.

77. Cooper JS, Pajak TF, Forastiere AA, Jacobs J, Campbell BH, Saxman SB, et al. Postoperative concurrent radiotherapy and chemotherapy for high-risk squamous-cell carcinoma of the head and neck. N Engl J Med. 2004;350(19):1937-44.

78. Curran D, Giralt J, Harari PM, Ang KK, Cohen RB, Kies MS, et al. Quality of life in head and neck cancer patients after treatment with high-dose radiotherapy alone or in combination with cetuximab. J Clin Oncol. 2007;25(16):2191-7.

79. Lorch JH, Goloubeva O, Haddad Rl, Cullen K, Sarlis N, Tishler R, et al. Induction chemotherapy with cisplatin and fluorouracil alone or in combination with docetaxel in locally advanced squamous-cell cancer of the head and neck: long-term results of the TAX 324 randomised phase 3 trial. Lancet Oncol. 2011;12(2):153-9.

\section{Submit your next manuscript to BioMed Central and we will help you at every step:}

- We accept pre-submission inquiries

- Our selector tool helps you to find the most relevant journal

- We provide round the clock customer support

- Convenient online submission

- Thorough peer review

- Inclusion in PubMed and all major indexing services

- Maximum visibility for your research

Submit your manuscript at www.biomedcentral.com/submit
Biomed Central 